\title{
Upregulation of AGR2vH facilitates cholangiocarcinoma cell survival under endoplasmic reticulum stress via the activation of the unfolded protein response pathway
}

\author{
GUNTICHA SUWANMANEE ${ }^{1}$, JUTHAMAS YOSUDJAI ${ }^{1}$, SUCHADA PHIMSEN $^{1}$, SOPIT WONGKHAM ${ }^{2,3}$, \\ SIWANON JIRAWATNOTAI $^{4}$ and WORASAK KAEWKONG ${ }^{1,3}$ \\ ${ }^{1}$ Department of Biochemistry, Faculty of Medical Science, Naresuan University, Phitsanulok 65000; \\ ${ }^{2}$ Department of Biochemistry, Faculty of Medicine; ${ }^{3}$ Cholangiocarcinoma Research Institute, Khon Kaen University, \\ Khon Kaen 40002; ${ }^{4}$ Siriraj Center of Research for Excellence for Systems Pharmacology, Department of Pharmacology, \\ Faculty of Medicine, Siriraj Medical School, Mahidol University, Bangkok 10700, Thailand
}

Received June 13, 2019; Accepted November 28, 2019

DOI: $10.3892 / \mathrm{ijmm} .2019 .4432$

\begin{abstract}
Cholangiocarcinoma (CCA) is an epithelial cell malignancy arising within the biliary tree in the liver. CCA is usually diagnosed at an advanced stage, subsequent to developing with metastasis. Recently, anterior gradient-2 (AGR2) was characterized as one of the most highly upregulated genes among all metastasis-associated genes in highly metastatic CCA cell lines. Previous reports have demonstrated that AGR2 is required for triggering the unfolded protein response (UPR) pathway to support cancer cell survival, particularly under endoplasmic reticulum (ER) stress conditions. A previous study identified an AGR2 short isoform generated by aberrant splicing, AGR2vH, which contributed to the metastatic phenotype of CCA cells. The aim of the present study was to determine the function of AGR2vH in UPR pathway activation to support cancer cell survivability and apoptosis evasion. Subsequent to experimentally inducing ER stress in AGR2vH-overexpressing CCA cells using tunicamycin, the UPR pathway was activated by the upregulation of UPR
\end{abstract}

Correspondence to: Professor Worasak Kaewkong, Department of Biochemistry, Faculty of Medical Science, Naresuan University, 99 Moo 9 Siharajdachochai Road, Phitsanulok 65000, Thailand E-mail: worasakk@nu.ac.th

Abbreviations: AGR2, anterior gradient-2; AGR2vH, anterior gradient-2 spliced variant $\mathrm{H}$; ATF6, activating transcription factor 6; BAX, Bcl-2-associated $\mathrm{X}$ protein; Bcl-2, B-cell leukemia/lymphoma 2; BiP/GRP78, binding immunoglobulin protein/glucose-regulated protein 78; CCA, cholangiocarcinoma; CHOP, C/EBP homologous protein; eIF2, Eukaryotic initiation factor 2; GPR94, glucose-regulated protein 94; IRE1, inositol-requiring enzyme 1; PERK, protein kinase RNA-like endoplasmic reticulum kinase; XBP1, X-box binding protein

Key words: aberrant splicing, anterior gradient-2, cholangiocarcinoma, endoplasmic reticulum stress marker genes (activating transcription factor 6, eukaryotic initiation factor $2 \mathrm{a}$ and spliced X-box binding protein 1), UPR proteins [binding immunoglobulin protein/glucose-regulated protein (GRP)78 kDa and phosphorylated eukaryotic translation initiation factor 2a] and UPR downstream targets (GRP94). In addition, the results were verified by AGR2vH knockdown using specific small interfering RNAs. Under ER stress conditions, the overexpression of AGR2vH reduced the number of apoptotic cells by decreasing caspase-3/7 activity and downregulating $\mathrm{C} / \mathrm{EBP}$ homologous protein $\mathrm{mRNA}$ and B-cell lymphoma-2 (Bcl-2)-associated $\mathrm{X}$ protein expression, whereas the $\mathrm{Bcl}-2$ protein was upregulated, resulting in a higher number of viable cells. The results of the present study support the previous data that indicate that an oncogenic AGR2vH isoform may not only promote metastasis-associated phenotypes, but also CCA cell survival and apoptosis evasion, thereby favoring cancer progression.

\section{Introduction}

Cholangiocarcinoma (CCA), or bile duct cancer, arises from the epithelium in the biliary tract. CCA development has been associated with infection by carcinogenic liver flukes, Opisthorchis viverrini, therefore, this type of cancer exhibits the highest incidence and mortality rates in Southeast Asia, particularly in Thailand (1). Diagnosis and treatment of CCA is difficult in a majority of cases, as the cancer is often detected when the patients are at an advanced stage, with metastases to the liver, lungs, lymph nodes or other secondary organs $(2,3)$. A previous model was established for studying the in vitro metastasis of CCA using a pair of human CCA cell lines without and with high metastatic activity, namely KKU-213 and KKU-213L5, respectively. KKU-213 is the parental cell line and KKU-213L5 was selected in vivo through the fifth serial passage of tissues from pulmonary metastases formed following the tail vein injection in NOD/scid/Janus kinase 3 mice. KKU-213L5 cells were revealed to exhibit the most prominent metastatic phenotype compared with the parental KKU-213 cells. The mRNA expression profiles of 77 
metastasis associated genes were determined using a quantitative (q)PCR array, which revealed that anterior gradient-2 (AGR2) was the most highly upregulated among 77 genes that were predominantly upregulated in KKU-213L5 cells compared with parental KKU-213 cells (4).

AGR2 is a protein that localizes in the anterior border of the embryonic ectoderm and is crucial in cementing gland development in the early embryonic development in Xenopus laevis (5). Human AGR2 is classified as an enzyme in the protein disulfide isomerases (PDIs) family. The 13,304 base pair (bp) of the AGR2 gene on chromosome 7 encodes for a 996-bp 8-exon mRNA, which translates into a 175 -amino acid protein (6). AGR2 is typically localized in the endoplasmic reticulum (ER) and is involved in the production of cysteine-rich proteins, including the mucin family in mucus-secreting cells/tissues, including the respiratory tract, stomach, colon, prostate gland and female reproductive system, and is highly expressed in various types of cancer tissues (7).

With regards to the functional involvement of AGR2 in ER, it directly functions as the isomerase enzyme for the folding of proteins and corrects protein misfolding by catalyzing the cysteine disulfide bond to produce productive functional proteins (8). Under abnormal conditions in humans, including cancer, the upregulation of AGR2 is associated with disease development and progression, and it has been revealed to promote pancreatic cancer cell proliferation and survival (9). In addition, the dimerization of monomeric AGR2 is required, particularly when the cells are under ER stress. For example, cancer cells exhibit a marked increase in their protein synthesis ability to support cell proliferation, resulting in the accumulation of proteins in the ER for post-translational modification into functional proteins (10). ER stress is caused by an accumulation of unfolded proteins or the presence of mutated proteins, which cannot fold correctly, and AGR2 is a key enzyme that serves an important function in protein-folding homeostasis under these ER conditions (8). A previous study demonstrated that an AGR2 homodimer is required to interact with binding immunoglobulin protein $(\mathrm{BiP}) /$ glucose-regulated protein $78 \mathrm{kDa}$ (GRP78) to activate the unfolded protein response (UPR) pathway, a cellular stress response mechanism that is directly associated with ER stress (10). The UPR pathway is initiated by three ER transmembrane-resident proteins, including inositol-requiring enzyme 1 (IRE1), activating transcription factor 6 (ATF6) and protein kinase RNA-like endoplasmic reticulum kinase (PERK). Under non-stress conditions, the three ER-transmembrane-resident proteins bind with $\mathrm{BiP}$ or GRP78 to remain inactive. Under ER stress conditions, BiP dissociates from these ER-transmembrane sensors, resulting in their activation (11). Activated IRE1 induces the splicing of X-box binding protein 1 (XBP1) mRNA to XBP1s, which translocates to the nucleus and functions as a transcription factor for the upregulation of UPR target genes (12). Activated ATF6 translocates to nucleus to function as a transcription factor, which modulates the expression of the chaperones and enzymes required for ER function (13). One of the downstream targets of ATF6 is GRP94, which is upregulated for the folding of newly synthesized proteins and prevents the accumulation of unfolded or misfolded proteins (14). Activated PERK phosphorylates a downstream target, eukaryotic initiation factor 2 (eIF2), and phosphorylated (p-)eIF2 $\alpha$ promotes the expression of transcription factor ATF4, which regulates numerous UPR pathway target genes involved in ER stress-mediated apoptosis, including $\mathrm{C} / \mathrm{EBP}$ homologous protein (CHOP) (15).

In 2014, the first evidence of AGR2 splicing was reported in prostate cancer, including 6 spliced variant transcripts, including AGR2vB, AGR2vC, AGR2vE, AGR2vF, AGR2vG and AGR2vH (16). A previous study reported the aberrant splicing of AGR2 in CCA cells, which characterized the highly upregulated AGR2vH transcript and its function in promoting the metastasis-associated phenotypes of CCA cells, including migration, invasion and adhesion capacities. Of note, only AGR2vH was predictably translatable into a protein isoform that consists of 67 amino acids, which were truncated from 175 amino acids in AGR2 $(17,18)$. The oncogenic properties of AGR2 $\mathrm{vH}$, which enhance the metastatic ability of CCA cells, were recently demonstrated (17). It was previously reported that the suppression of AGR2 $\mathrm{vH}$ in highly metastatic KKU-213L5 cells reduced their migration and invasion abilities, whereas the overexpression of AGR2vH in parental KKU-213 cells promoted cancer cell migration, invasion, adhesion and proliferation (17).

Regarding the characterization of AGR2, it is a gene that is highly and specifically upregulated in the metastatic CCA cell line (4) and the upregulation of this gene coincides with the aberrant splicing of AGR2 mRNA, and AGR2vH are specific to metastatic CCA cells (17). Previous results have demonstrated that the AGR2vH isoform enables metastatic-associated phenotypes in CCA cells. Additionally, another important function of AGR2vH was proposed (17). Taking into account experiments in other cancer types that proved that the AGR2 wild-type is required for interaction with BiP/GRP78, which is the UPR pathway activator as mentioned above (10), the present study attempted to investigate the functional ability of AGR2 $\mathrm{vH}$ in the activation of the UPR pathway in a model of CCA.

Prospectively, AGR2vH may serve as an alternative partner molecule contributing to the survival of CCA cells. The aim of the present study was to determine the effect of AGR2vH on UPR pathway response and cell viability/apoptosis following the overexpression and knockdown of AGR2vH in CCA cells, particularly when experimentally inducing ER stress in the cancer cells. The activation of the UPR pathway was investigated by the expression of UPR-sensitive markers and UPR pathway activation proteins. In addition, the number of dead cells and the activity of caspase enzymes in the apoptosis pathway and the survival of CCA cells were investigated.

\section{Materials and methods}

Cell lines and cell culture. The two CCA cell lines used in the present study included KKU-213, which was obtained from the Japanese Collection of Research Bioresources Cell Bank, and KKU-213L5, a highly metastatic CCA cell line derived from the parental KKU-213 cell, which was established in a previous study (4). Cells were provided from the Cholangiocarcinoma Research Institute, Faculty of Medicine, Khon Kaen University (Khon Kaen, Thailand). The cell lines were cultured in Dulbecco's modified Eagle's medium supplemented with $10 \% \mathrm{v} / \mathrm{v}$ fetal bovine serum with $100 \mathrm{U} / \mathrm{ml}$ penicillin and $100 \mu \mathrm{g} / \mathrm{ml}$ streptomycin (Gibco; Thermo Fisher 
Scientific, Inc.) and maintained at $37^{\circ} \mathrm{C}$ in a humidified incubator in a $5 \% \mathrm{CO}_{2}$ atmosphere.

Transfection and overexpression of AGR2vH in CCA cells. AGR2vH-overexpressing KKU-213 cells were established as previous described (17). Briefly, AGR2vH mRNA was amplified by specific primers, as listed in Table I, with the relevant restriction sites to clone into the $\mathrm{pCR}^{\circledR} 2.1-\mathrm{TOPO}^{\circledR}$ cloning vector (Invitrogen; Thermo Fisher Scientific, Inc.). The AGR2vH nucleotide sequences were analyzed and confirmed before being sub-cloned into the p3XFLAG-CMV-14 expression vector (Sigma-Aldrich; Merck KGaA). Either pCMV14-AGR2vH or pCMV14-Empty vector $(5 \mu \mathrm{g} / \mu \mathrm{l})$ were transfected into KKU-213 cells by Lipofectamine 2000 (Thermo Fisher Scientific, Inc.) and cultured for $48 \mathrm{~h}$ at $37^{\circ} \mathrm{C}$, and the single clones were selected using $2 \mathrm{mg} / \mathrm{ml}$ Geneticin G418 (Thermo Fisher Scientific, Inc.) and subjected to expansion and culture.

Experimental induction of ER stress. Tunicamycin was used to block the activity of glycosylase, which resulted in the accumulation of unglycosylated-proteins in the ER. Tunicamycin (Sigma-Aldrich; Merck KGaA) was dissolved in dimethyl sulfoxide. The optimal concentration was determined by testing tunicamycin at $0.5,1,2,4$ and $8 \mu \mathrm{g} / \mu \mathrm{l}$ in culture media for $24 \mathrm{~h}$, in order to examine cytotoxicity using an MTT assay (Bio Basic, Inc.), as previously described (19) (data not shown). The resulting formazan crystals were dissolved in DMSO and the absorbance at $540 \mathrm{~nm}$ was measured by using a Synergy HT Multi-Detection Microplate Reader (BioTek Instruments, Inc.) Subsequently, the expression of ER stress-sensitive markers, including XBP1s and BiP/GRP78, was determined by reverse transcription (RT)-PCR and qPCR.

Depletion of AGR2vH by small interfering RNA (siRNA). AGR2vH-overexpressing cells were transfected withsiAGR2vH (antisense: 5'-UUGAGAGCUUUCUUCAUAUGUCUG-3') as previously described (17). Briefly, AGR2vH-overexpressing cells were plated in a 6 -well plate at $2.5 \times 10^{4}$ cells per well for $24 \mathrm{~h}$. Then, the cells were transfected with $75 \mathrm{nmol}$ siAGR2vH or negative control siRNA (Ambion; Thermo Fisher Scientific, Inc.) using Lipofectamine 2000 (Thermo Fisher Scientific, Inc.) in Opti-MEM I reduced-serum medium (Gibco; Thermo Fisher Scientific, Inc.) and incubated for $6 \mathrm{~h}$ at $37^{\circ} \mathrm{C}$. After that, the media was removed and replaced with fresh complete media. At $48 \mathrm{~h}$ after transfection, cells were harvested for used in further experiments.

Preparation of RNA and RT-PCR. Total RNA was isolated from the cells using an E.Z.N.A ${ }^{\circledR}$ Total RNA kit I (Omega Bio-Tek, Inc.). The concentrations of RNA samples were measured, and $1 \mu \mathrm{g}$ total RNA was used to synthesize the complementary DNA using the HisenScriptTM RH [-] RT PreMix kit (Intron Biotechnology, Inc.) according to the manufacturer's protocol. All cDNA samples were stored at $-80^{\circ} \mathrm{C}$ until use. For the determination of gene expression by the amplification of synthesized cDNA, PCR was performed under optimized conditions. The reaction mixture contained $0.2 \mu \mathrm{g}$ cDNA template, $0.4 \mu \mathrm{M}$ each the forward and reverse primers with a total volume of
$20 \mu 1$ of 1X MyTaqTM HS Red Mix (Bioline Reagents Limited). The house-keeping gene $\beta$-actin was used as an internal control for semi-quantitative normalization. The primers for the target genes were based on previous studies including AGR2vH (17), XBP1 (20), BiP/GRP78 (11), ATF6, CHOP (21), eIF2a and GRP94 (22) and are listed in Table I. The thermocycling conditions were as follows: $95^{\circ} \mathrm{C}$ for $5 \mathrm{~min}$ for a pre-denature, followed by 30 cycles of $95^{\circ} \mathrm{C}$ for $30 \mathrm{sec}, 55^{\circ} \mathrm{C}$ for $30 \mathrm{sec}$ and $72^{\circ} \mathrm{C}$ for $30 \mathrm{sec}$, and final extension at $72^{\circ} \mathrm{C}$ for $5 \mathrm{~min}$. The PCR products were mixed with $6 \mathrm{X}$ non-mutagenic fluorescent (SYBR-Green) DNA staining reagent (Novel Juice, Gene DireX, Inc.) and analyzed by $2 \%$ agarose gel electrophoresis at 90 volts for $30 \mathrm{~min}$ and visualized under ultraviolet illumination of agarose gels detected by ImageQuant ${ }^{\mathrm{TM}}$ LAS 500 (GE Healthcare Life Sciences) and quantitated using ImageQuant TL 7.0 software (GE Healthcare Life Sciences).

$q P C R$. qPCR was performed for the relative quantification of gene expression, including AGR2vH expression in AGR2vH-overexpressing cells and the expression of ER stress-sensitive markers. The reaction mixture $(10 \mu \mathrm{l})$ contained a cDNA template, forward and reverse primers for each target gene (Table I) and 1X LightCycler ${ }^{\circledR} 480$ SYBR Green I Master (Roche Applied Science). Primers for the target genes were based on previous studies including XBP1s (23) and BiP/GRP78. The thermocycling conditions were as follows: $95^{\circ} \mathrm{C}$ for $10 \mathrm{~min}$, followed by 45 cycles of $95^{\circ} \mathrm{C}$ for $10 \mathrm{sec}, 60^{\circ} \mathrm{C}$ for $10 \mathrm{sec}$ and $72^{\circ} \mathrm{C}$ for $10 \mathrm{sec}$. All reactions were experimentally performed in biological triplicate and analyzed using the LightCycler ${ }^{\circledR} 480$ systems (Roche Applied Science). The expression levels of the target genes were normalized with $\beta$-actin using the relative quantification formula of $2^{-\Delta \Delta \mathrm{Cq}}(24)$.

Protein extraction and western blot analysis. Cells were lysed with lysis buffer containing 7M urea, $2 \mathrm{M}$ thiourea, 4\% 3-[3-cholamidopropyl)dimethylammonio]-1-propanesulfonate, and protease and phosphatase inhibitors (Roche Diagnostics). The protein concentration was determined using the Bradford assay (Bio-Rad Laboratories, Inc.). Equal amounts of protein (30 $\mu \mathrm{g} /$ lane) were separated by $12 \%$ SDS-PAGE and western blot analysis were performed as previously described (17). Briefly, membranes were blocked with 5\% non-fat milk in TBST for $2 \mathrm{~h}$ at room temperature. Subsequently, membranes were incubated with primary antibodies overnight at $4^{\circ} \mathrm{C}$ and incubated with secondary antibodies for $1 \mathrm{~h}$ at room temperature. Antibodies against BiP/GRP78 (cat no. E-AB-31742; 1:2,000), p-eIF2a (cat no. E-AB-20864; 1:2,000), B-cell lymphoma-2 (Bcl-2; cat no. E-AB-15522; 1:650) and Bcl-2-associated X (BAX; cat no. E-AB-30629; 1:1,000) were purchased from Elabscience (Houston, TX, USA) whereas antibodies for $\beta$-actin (cat no. A5441; 1:1,000), horseradish peroxidase (HRP)-conjugated anti-rabbit immunoglobulin G (IgG) (cat no. AP182P; 1:5,000) and HRP-conjugated anti-mouse IgG (cat no. 12-349; 1:5,000) were purchased from Sigma-Aldrich; Merck KGaA. Protein bands were detected with an enhanced chemiluminescence system (Bio-Rad Laboratories, Inc.) and visualised with ImageQuant ${ }^{\mathrm{TM}}$ LAS 500 (GE Healthcare Life Sciences). 
Table I. Primer sequences for reverse transcription-PCR and quantitative PCR.

\begin{tabular}{lll}
\hline Name & \multicolumn{1}{c}{ Forward primer 5'-3' } & \multicolumn{1}{c}{ Reserve primer 5'-3' } \\
\hline $\begin{array}{l}\text { AGR2vH } \\
\text { AGR2vH } \\
\text { (with restriction sites) }\end{array}$ & CAGACATATGAAGAAAGCTCTCAAGT & TCCACACTAGCCAGTCTTCTCA \\
ATF6 & AAGCTTATGGAGAAAATTCCAGTGTC & GAATTCGTCTTCAGCAACTTG \\
BiP/GRP78 & GAACCATTGCTTTACATTCCTCCAC & CTGCTTGACTTGGTCCTTTCTACTTC \\
CHOP & GTTCTTCAATGGCAAGGAACCATCTC & CCATCCTTTCGATTTCTTCAGGTGGAA \\
eIF2 & TGAACGGCTCAAGCAGGAAATCG & GGATTGAGGGTCACATCATTGGCACT \\
GRP94 & GCCAAATTGCCCTATCTCAA & CAGAAAAATGGGCAAAGGAA \\
XBP1 & TGGGAAGAGGTTCCAGAATG & GTTGCCAGACCATCCGTACT \\
XBP1s & TTACGAGAGAAAACTCATGGCC & GGGTCCAAGTTGTCCAGAATGC \\
-actin & TGCTGAGTCCGCAGCAGGT & GCTGGAGGCTCTGGGGAA \\
\hline
\end{tabular}

AGR2vH, Anterior gradient-2 spliced variant H; ATF6, Activating transcription factor 6; BiP, Binding immunoglobulin protein; GRP, Glucose-regulated protein; CHOP, C/EBP homologous protein; eIF2, Eukaryotic initiation factor 2; XBP1s, spliced X-box binding protein 1.
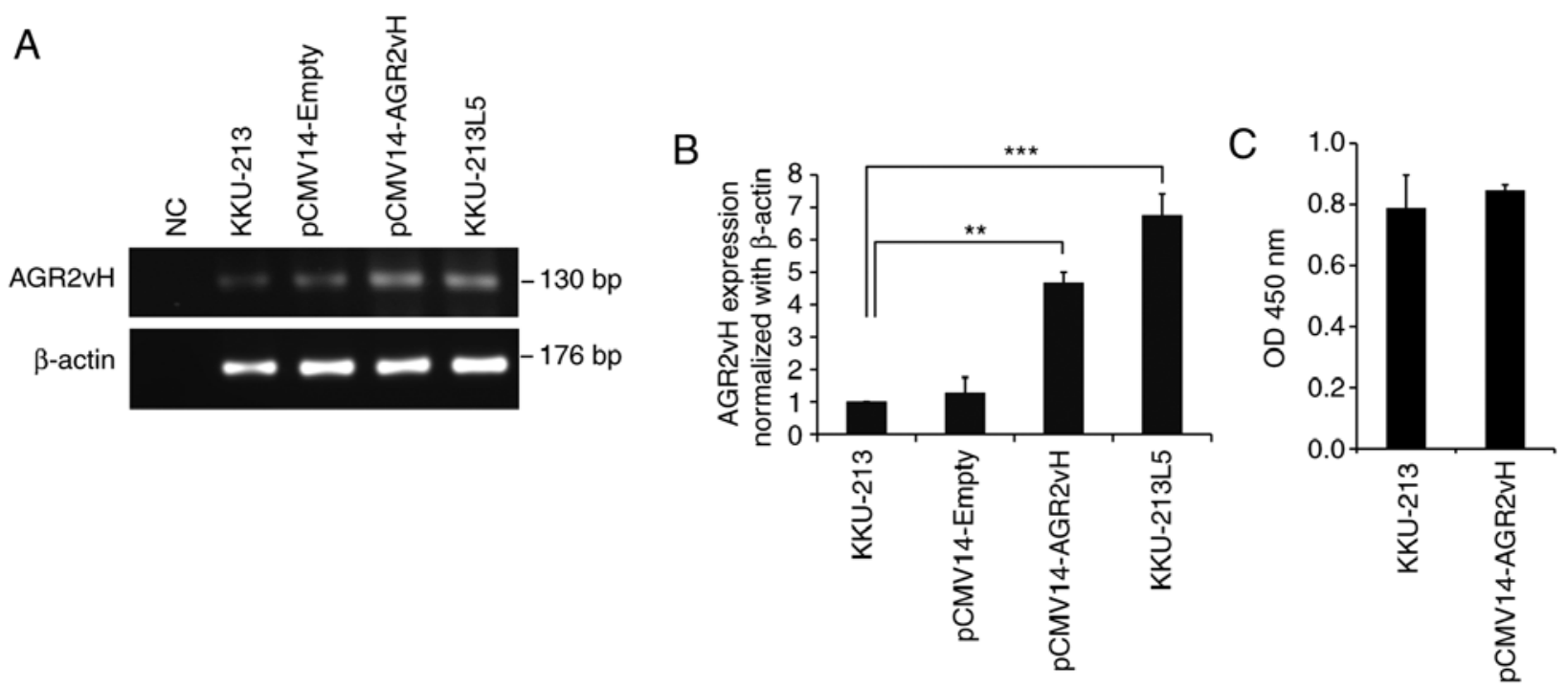

Figure 1. Expression of AGR2vH in AGR2vH-overexpressing cells. (A) Semi-quantitative reverse transcription-PCR (B) Quantitative PCR of AGR2vH in KKU-213 (untransfected control, empty vector transfected- and AGR2vH-overexpressing cells) and KKU-213L5 cells. (C) Cell viability subsequent to transfection. The viability of AGR2vH-overexpressing cells was not significantly altered at $48 \mathrm{~h}$ post-transfection compared with KKU-213 cells as determined using the Cell Counting Kit- 8 assay. The data in $\mathrm{B}$ and $\mathrm{C}$ are presented as the mean \pm standard deviation. ${ }^{* *} \mathrm{P}<0.01$ and ${ }^{* * * *} \mathrm{P}<0.001$ with comparisons shown by lines. AGR2vH, Anterior gradient-2 spliced variant $\mathrm{H}$; $\mathrm{NC}$, negative control; OD, optical density.

Flow cytometry. Apoptosis was assessed by Annexin V-Phy coerythrin/7-Amino-Actinomycin staining using a Muse ${ }^{\mathrm{TM}}$ Annexin V and Dead Cell assay kit (Merck KGaA). Cells were plated in a 6 -well plate at $2.5 \times 10^{5}$ cells per well for $24 \mathrm{~h}$ prior to tunicamycin treatment. After $24 \mathrm{~h}$ treatment at $37^{\circ} \mathrm{C}, 100 \mu \mathrm{l}$ Muse $^{\mathrm{TM}}$ Annexin V \& Dead Cell reagent and an equal volume of $4 \times 10^{5}$ cells from each of the groups were mixed. Subsequent to incubating for $20 \mathrm{~min}$ at room temperature, the numbers of live, dead and apoptotic cells were analyzed using Muse ${ }^{\circledR}$ Cell Analyzer and Muse 1.5.0.0 Analysis software (Merck $\mathrm{KGaA})(25)$.

Caspase 3/7 activity assay. Cells were plated in a 96-well black plate at $2 \times 10^{4}$ cells per well for $24 \mathrm{~h}$ prior to tunicamycin treatment. After $24 \mathrm{~h}$ treatment, caspase 3/7 activities were analyzed using an Apo-ONE ${ }^{\circledR}$ Homogeneous caspase 3/7 assay (Promega Corporation), based on the cleavage of the non-fluorescent caspase substrate Z-DEVD-R110 by caspase-3/7 to create fluorescent Rhodamine 110 (26), according to the manufacturer's protocol. The fluorescence signal of each well was measured by a fluorescence microplate reader (EnSpire Multimode Plate reader; PerkinElmer, Inc.). With regards to the measurement of the fluorescence intensities, the assay suggested that the excitation wavelength be set at $499 \mathrm{~nm}$, and the emission wavelength at $521 \mathrm{~nm}(27,28)$.

Cell viability assay. Cells were plated in a 96-well plate at $3 \times 10^{3}$ cells per well for $24 \mathrm{~h}$ prior to tunicamycin treatment. After $24 \mathrm{~h}$ treatment, $10 \mu \mathrm{l}$ Cell Counting Kit-8 (CCK-8) reagent (Sigma-Aldrich; Merck KGaA) was added to each 
A
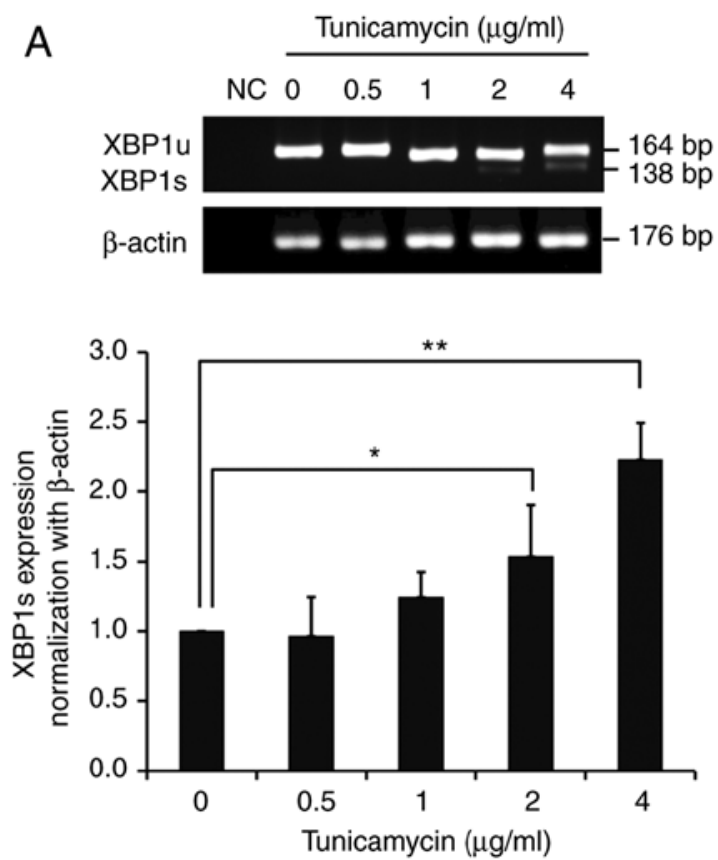

B
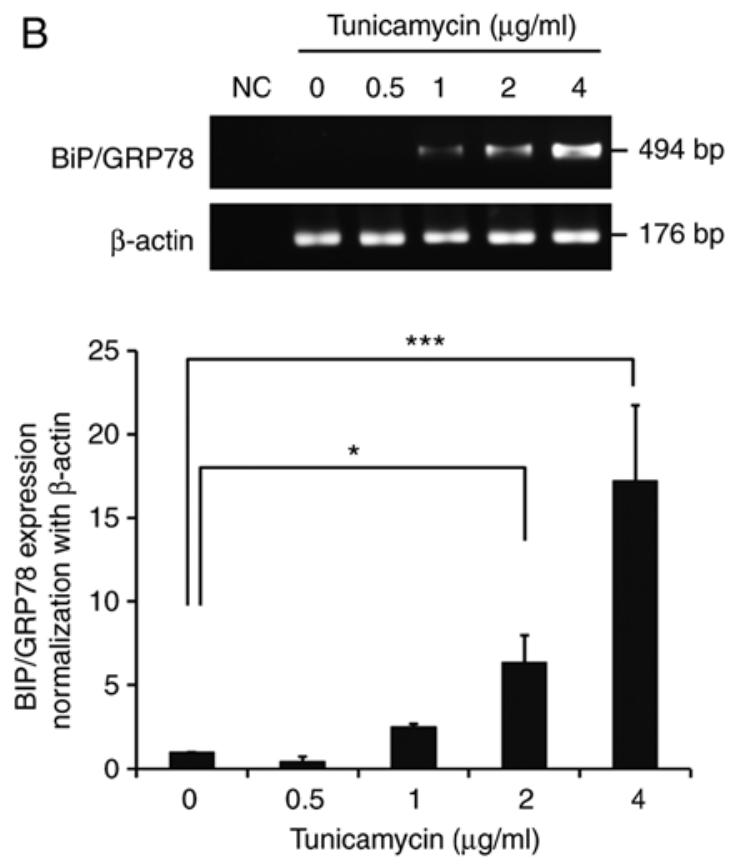

Figure 2. Effects of tunicamycin on the expression of endoplasmic reticulum stress markers. (A) Expression of XBP1 (XBP1u and XBP1s) using RT-PCR and of XBP1s using qPCR. (B) Expression of BiP/GRP78 after $24 \mathrm{~h}$ tunicamycin treatment at $0.5,1,2$ and $4 \mu \mathrm{g} / \mathrm{ml} \mathrm{using}$ RT-PCR and qPCR. All data are presented as the mean \pm standard deviation. ${ }^{*} \mathrm{P}<0.05,{ }^{* *} \mathrm{P}<0.01$ and ${ }^{* * * *} \mathrm{P}<0.001$ with comparisons shown by lines. $\mathrm{XBP} 1 \mathrm{u}$, unspliced $\mathrm{X}-$ box binding protein 1 ; XBP1s, spliced X-box binding protein 1; BiP, Binding immunoglobulin protein; GRP, Glucose-regulated protein; RT-PCR, reverse transcription-PCR; qPCR, quantitative PCR; bp, base pairs; NC, negative control.

well. Cells were incubated for $4 \mathrm{~h}$ at $37^{\circ} \mathrm{C}$, and the absorbance at $450 \mathrm{~nm}$ was measured using a Synergy HT Multi-Detection Microplate Reader (BioTek Instruments, Inc.).

Statistical analysis. Experiments were performed in biological triplicate. Data were calculated and presented as the mean \pm standard deviation. Statistical significance between two groups was determined using a Student's t-test (two tailed). One-way analysis of variance with a Least Significant Difference post-hoc test was performed to compare multiple groups using SPSS 17 (SPSS, Inc.). $\mathrm{P}<0.05$ was considered to indicate a statistically significant difference.

\section{Results}

Expression of AGR2vH on AGR2vH-overexpressing cells. Semi-quantitative RT-PCR was performed to evaluate the expression of AGR2vH once the cells were transfected with pCMV14-Empty and pCMV14-AGR2vH vector. The expression of AGR2vH was substantially increased in AGR2vH-overexpressing cells when compared with the untransfected control cells, but the expression level of AGR2vH in AGR2vH-overexpressing cells was still lower compared with KKU-213L5 cells (Fig. 1A). Furthermore, RT-qPCR confirmed the results of RT-PCR $(\mathrm{P}<0.01$; Fig. 1B). In addition, the cell viability following AGR2vH transfection into KKU-213 cells was not significantly altered at $48 \mathrm{~h}$ post-transfection compared with KKU-213 cells (untransfected control) (Fig. 1C).

Experimentally induced ER stress. To optimize the different concentrations of tunicamycin, the expression of ER stress markers (XBP1s and BiP/GRP78) was determined after $24 \mathrm{~h}$ treatment using $<4 \mu \mathrm{g} / \mathrm{ml}$ tunicamycin. XBP1s was significantly upregulated at $2 \mu \mathrm{g} / \mathrm{ml}$ when compared with untreated cells, as demonstrated using RT-PCR and confirmed by qPCR $(\mathrm{P}<0.05$; Fig. 2A). Similar results were obtained for BiP/GRP78 by RT-PCR and qPCR ( $<<0.05$; Fig. 2B). Therefore, $2 \mu \mathrm{g} / \mathrm{ml}$ tunicamycin was selected for ER stress induction.

Activation of the UPR pathway and UPR downstream. The present study sought to investigate UPR response following AGR2vH overexpression and knockdown in CCA cells and UPR response under ER stress-inducing conditions. On determination of the UPR marker gene expression, the notable upregulation of XBP1s, ATF6 and eIF2a was observed when the AGR2vH-overexpressing cells were under ER stress conditions (Fig. 3A). Similar results were observed in AGR2vH-depleted cells, with the downregulation of these markers under ER stress conditions, particularly ATF6 and eIF2a (Fig. 3B). The expression of GRP94 mRNA, an ER chaperone downstream of the UPR pathway, was upregulated in AGR2vH-overexpressing cells (Fig. 3C) and downregulated in AGR2vH-depleted cells, particularly under ER stress conditions (Fig. 3D). In addition, the activation of the UPR pathway was confirmed by determination of BiP/GRP78 and p-eIF2a protein expression under ER stress-inducing conditions. It was revealed that BiP/GRP78 and p-eIF2a protein expression was upregulated in AGR2vH-overexpressing cells (Fig. 3E), whereas they were downregulated in AGR2vH-depleted cells (Fig. 3F).

Effects of AGR2vH on cell apoptosis. The apoptosis of CCA cells was determined using flow cytometry. Reduction of the apoptotic cell population, particularly cells in late apop- 

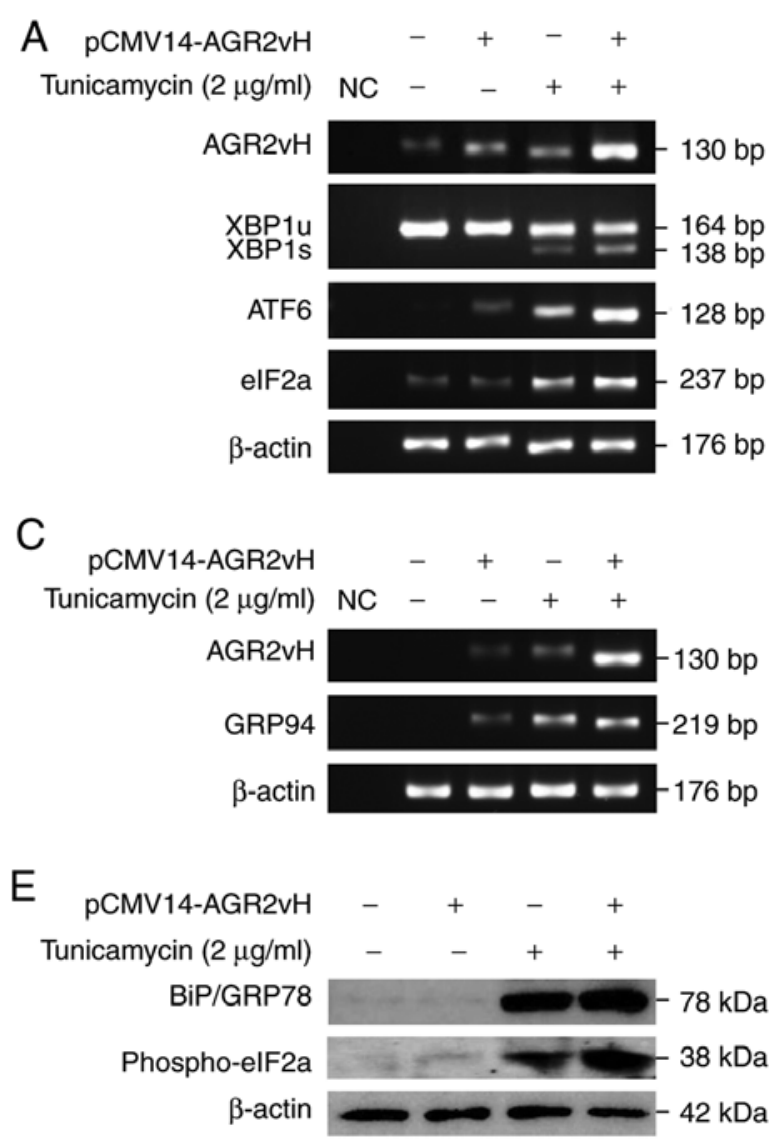
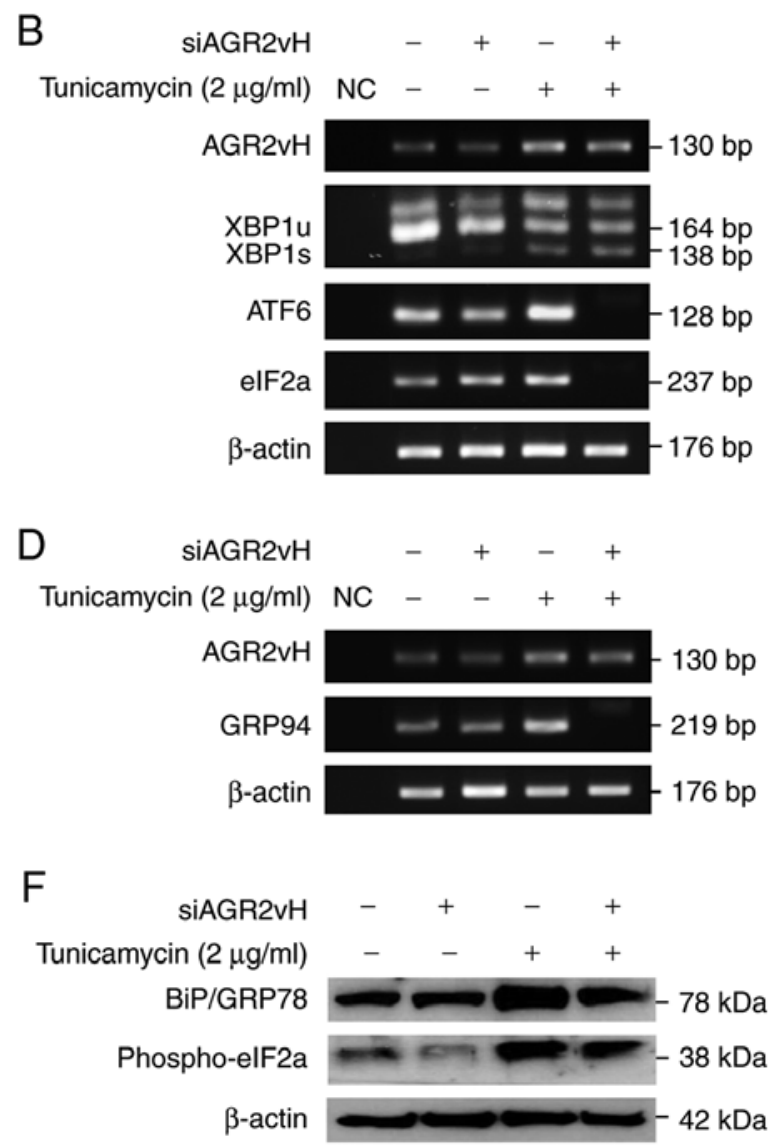

Figure 3. Status of UPR pathway activation and expression of UPR downstream markers in AGR2vH-overexpressing and AGR2vH-depleted cells. (A) mRNA expression of XBP1s, ATF6 and eIF2a in AGR2vH-overexpressing cells. (B) mRNA expression of XBP1s, ATF6 and eIF2a in AGR2vH-depleted cells. (C) mRNA expression of GRP94 in AGR2vH-overexpressing cells. (D) mRNA expression of GRP94 in AGR2vH-depleted cells. (E) Expression of BiP/GRP78 and p-eIF2a proteins in AGR2vH-overexpressing cells. (F) Expression of BiP/GRP78 and p-eIF2a proteins in AGR2vH-depleted cells. UPR, unfolded protein response; AGR2vH, Anterior gradient-2 spliced variant $\mathrm{H}$; XBP1s, spliced X-box binding protein 1; BiP, Binding immunoglobulin protein; GRP, Glucose-regulated protein; ATF6, Activating transcription factor 6; eIF2, Eukaryotic initiation factor 2; BiP, Binding immunoglobulin protein; GRP, Glucose-regulated protein; NC, negative control.

tosis, was observed in AGR2vH-overexpressing cells under ER stress-inducing conditions when compared with empty vector-transfected cells (Fig. 4A and B). The results were also confirmed by caspase 3/7 activities, which were significantly decreased in AGR2vH-overexpressing cells under ER stress conditions when compared with empty vector-transfected cells $(\mathrm{P}<0.001$; Fig. 4C). In addition, the present study observed the downregulation of CHOP mRNA, which is the ER stress-induced apoptosis gene (Fig. 4D), and upregulation of the anti-apoptotic Bcl-2 protein and downregulation of the apoptotic BAX protein (Fig. 4E), particularly when the AGR2vH-overexpressing cell were under ER stress.

Effects of AGR2vH on cell survival. The mRNA expression of AGR2vH was upregulated in AGR2vH-overexpressing cells under ER stress-inducing conditions, and downregulated in AGR2vH-overexpressing cells with AGR2vH depletion (Fig. 5A). The expression of AGR2vH was directly associated with the survival of CCA cells, which was determined using the CCK-8 assay. Cell survival was significantly increased with AGR2vH overexpression in cells under ER stress-inducing condition when compared with empty vector-transfected cells $(\mathrm{P}<0.01)$, while the cell viability of AGR2vH-overexpressing cells with AGR2vH depletion under ER stress-inducing conditions was significantly decreased when compared with AGR2vH-overexpressing cells ( $\mathrm{P}<0.001$; Fig. 5B).

\section{Discussion}

AGR2vH, produced from the aberrant splicing of AGR2, promotes the metastatic phenotype of CCA cells. Of note, only AGR2vH is predicted to be translatable into a 67-amino acid protein isoform (17). In addition, AGR2 $\mathrm{vH}$ was revealed to contribute to the migration and invasion of CCA cells $(17,18)$. The dimerization of AGR2 is required to activate the UPR pathway by interaction with BiP/GRP78 for the recovery of cellular ER stress and the increase of cancer cell survival (10). Prospectively, AGR2vH may serve as an alternative partner molecule, which may readily interact with BiP/GRP78 to activate the UPR pathway when ER stress occurs in cancer cells.

For the verification of ER stress, the BiP/GRP78 protein chaperone, which activates the UPR pathway, was upregulated. In addition, XBP1 was spliced, which removes a 26-nucleotide intron from XBP1 mRNA, into XBP1s, resulting in the increased expression of the chaperon proteins (29). In the present study, BiP/GRP78 and XBP1s were upregulated. In addition, AGR2 was demonstrated to be upregulated under ER stress conditions to facilitate protein 
A $\begin{array}{r}\text { pCMV14-AGR2vH } \\ \text { Tunicamycin }(2 \mu \mathrm{g} / \mathrm{ml})\end{array}$

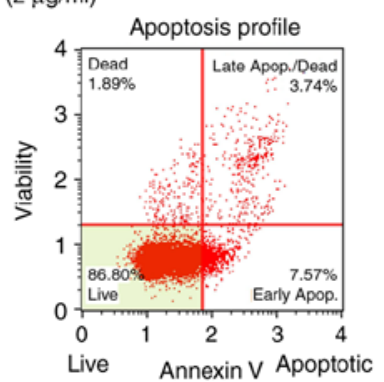

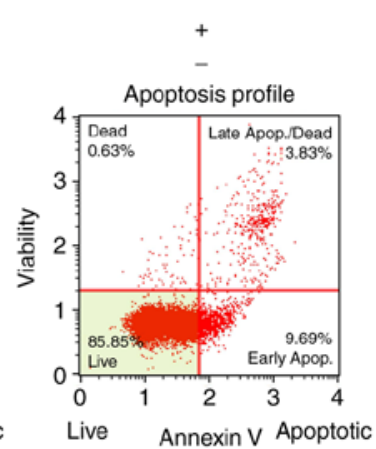

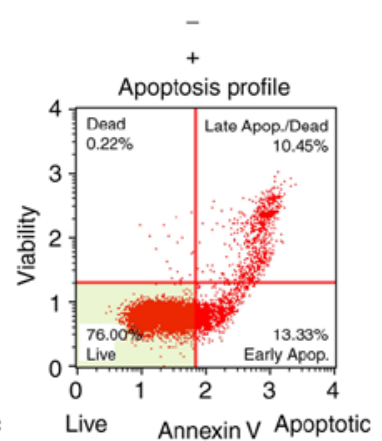

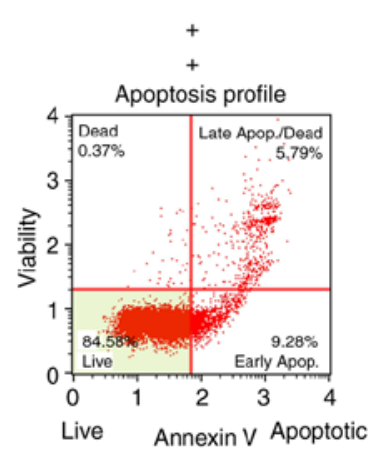
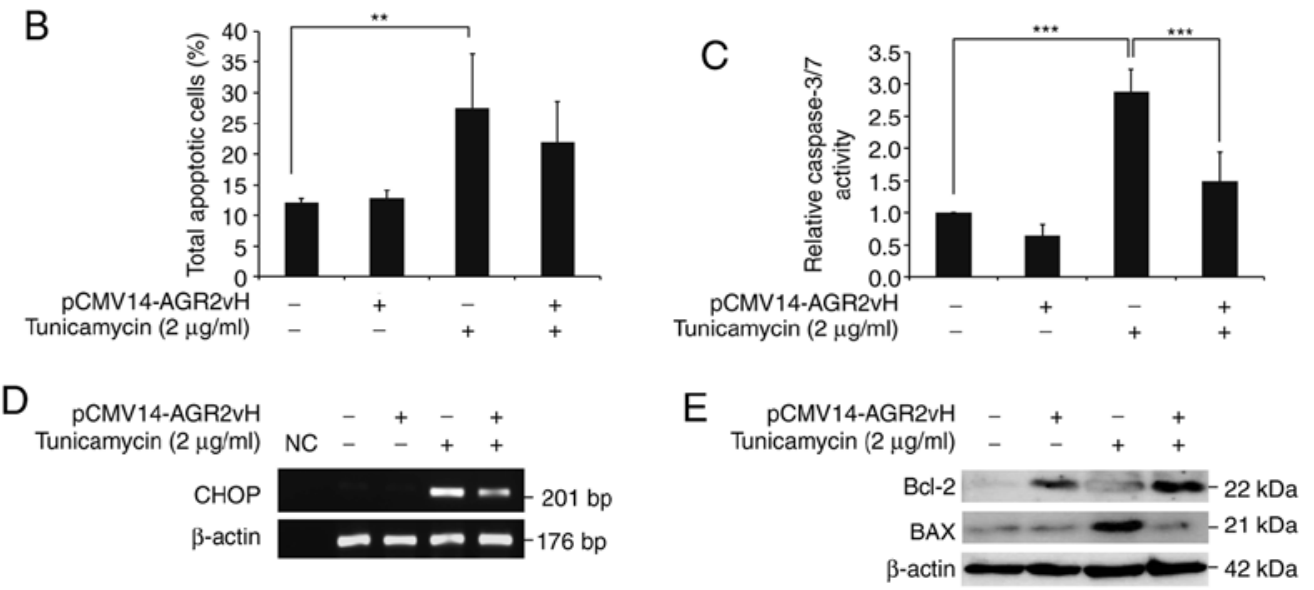

Figure 4. Overexpression of AGR2vH decreased cancer cell apoptosis under ER stress-inducing conditions. (A) Comparative determination of apoptotic cells among AGR2vH-overexpressing cells. (B) Quantitative analysis of the total apoptotic cells among AGR2vH-overexpressing cells. (C) Detection of caspase 3/7 activity in AGR2vH-overexpressing cells. (D) mRNA expression of CHOP, an ER stress-induced apoptosis gene. (E) Expression of anti-apoptotic protein $\mathrm{Bcl}-2$ and apoptotic protein $\mathrm{BAX}$. The data in $\mathrm{B}$ and $\mathrm{C}$ are presented as the mean \pm standard deviation. ${ }^{* *} \mathrm{P}<0.01$ and ${ }^{* * * *} \mathrm{P}<0.001$ with comparisons shown by lines. AGR2vH, Anterior gradient-2 spliced variant H; ER, endoplasmic reticulum; CHOP, C/EBP homologous protein; Bcl-2, B-cell lymphoma 2; BAX, Bcl-2-associated X protein; bp, base pair; NC, negative control.
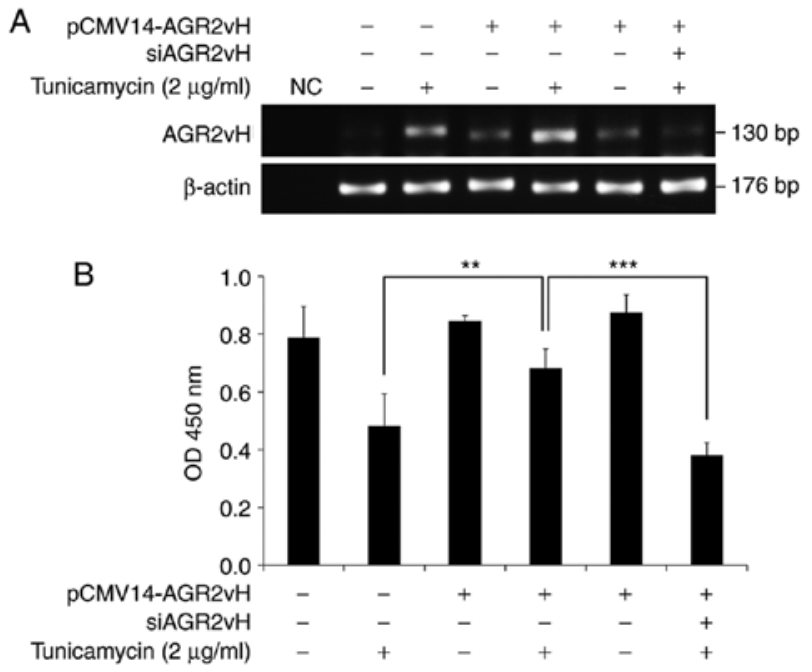

Figure 5. Overexpression of AGR2vH promotes cancer cell survival. (A) mRNA expression of AGR $2 \mathrm{vH}$ was upregulated in AGR 2vH-overexpressing cells under ER stress-inducing conditions, and downregulated in AGR2vH-overexpressing cells with AGR2vH depletion. (B) Viability of AGR2vH-overexpressing cells under ER stress-inducing condition was increased when compared with empty vector-transfected cells, while the viability of AGR2vH-overexpressing cells with depleted AGR2vH under ER stress-inducing conditions was decreased when compared with AGR2vH-overexpressing cells under ER stress-inducing conditions. The data in $\mathrm{B}$ are presented as the mean \pm standard deviation. ${ }^{* *} \mathrm{P}<0.01$ and ${ }^{* * *} \mathrm{P}<0.001$ with comparisons shown by lines. AGR2vH, Anterior gradient-2 spliced variant $\mathrm{H}$; ER, endoplasmic reticulum; si-, small interfering RNA; NC, negative control; OD, optical density. folding in the cells (30). In the present study, AGR2vH expression was induced.

The activation of the UPR pathway under ER stress conditions is based on three ER transmembrane receptors, namely IRE1, ATF6 and PERK (31). The present study investigated the expression of unspliced (XBP1u)/XBP1s downstream of IRE1. AGR2vH-overexpressing cells exhibited XBPlu downregulation and XBP1s upregulation, which induces the expression of genes involved in restoring protein folding, including BiP/GRP78 and PDIs (12). A previous study demonstrated that the expression of eIF2a, a downstream target of PERK, was upregulated following tunicamycin treatment (22). The present study reported that eIF2a mRNA and activated p-eIF2a protein were upregulated under conditions of ER stress by $2 \mu \mathrm{g} / \mathrm{ml}$ tunicamycin, and were upregulated in AGR2vH-overexpressing cells. Furthermore, in the present study, the expression of GPR94, a downstream target of ATF6 (32), was upregulated in association with the increased expression of ATF6.

In addition, the expression of $\mathrm{CHOP}$, a molecule involved in ER stress-induced apoptosis, is low under non-stress conditions but increases under ER stress conditions (33). In the present study, the expression of CHOP in CCA cells was upregulated under ER stress-inducing conditions, but was downregulated in AGR2vH-overexpressing cells. Of note, the present study also demonstrated changes in the expression of anti-apoptotic and apoptotic proteins, and revealed that the expression of 
Bcl-2 and BAX were associated with the survivability of CCA cells with AGR2vH overexpression and knockdown.

In conclusion, the upregulation of AGR2vH activated the UPR pathway and the expression of UPR downstream markers, decreasing cell apoptosis via decreased caspase-3/7 activity and contributing to the survival of CCA cells, particularly under ER stress-inducing conditions. These results support the potential application of this molecule as an alternative therapeutic target for CCA.

\section{Acknowledgements}

Not applicable.

\section{Funding}

The present study was supported by The Naresuan University Research Scholarship for Graduate Students, the Thailand Research Fund and Medical Research Council-UK (Newton Fund; grant no. DBG5980004) and the Thailand Research Fund and Office of the Higher Education Commission (grant no. TRF-MRG6080014).

\section{Availability of data and materials}

The datasets used and/or analyze during the current study are available from the corresponding author on reasonable request.

\section{Authors' contributions}

WK and SP designed the experiments. GS and JY performed the experiments. GS and WK contributed to data acquisition and wrote the manuscript. SW contributed to project design and edited the manuscript. SJ made substantial contributions to conception and design, and revised the manuscript for important intellectual content. All authors have read and approved the manuscript, and agree to be accountable for all aspects of the research in ensuring that the accuracy and integrity of any part of the work are appropriately investigated and resolved.

\section{Ethics approval and consent to participate}

Not applicable.

\section{Patient consent for publication}

Not applicable.

\section{Competing interests}

The authors declare that they have no competing interests.

\section{References}

1. Shin HR, Oh JK, Masuyer E, Curado MP, Bouvard V, Fang YY, Wiangnon S, Sripa B and Hong ST: Epidemiology of cholangiocarcinoma: An update focusing on risk factors. Cancer Sci 101: 579-585, 2010.

2. Sripa B and Pairojkul C: Cholangiocarcinoma: Lessons from thailand. Curr Opin Gastroenterol 24: 349-356, 2008.
3. Sripa B, Bethony JM, Sithithaworn P, Kaewkes S, Mairiang E, Loukas A, Mulvenna J, Laha T, Hotez PJ and Brindley PJ: Opisthorchiasis and opisthorchis-associated cholangiocarcinoma in Thailand and Laos. Acta Trop 120 (Suppl 1): S158-S168, 2011.

4. Uthaisar K, Vaeteewoottacharn K, Seubwai W, Talabnin C, Sawanyawisuth K, Obchoei S, Kraiklang R, Okada S and Wongkham S: Establishment and characterization of a novel human cholangiocarcinoma cell line with high metastatic activity. Oncol Rep 36: 1435-1446, 2016.

5. Aberger F, Weidinger G, Grunz H and Richter K: Anterior specification of embryonic ectoderm: The role of the Xenopus cement gland-specific gene XAG-2. Mech Dev 72: 115-130, 1998.

6. Petek E, Windpassinger C, Egger H, Kroisel PM and Wagner K: Localization of the human anterior gradient-2 gene (AGR2) to chromosome band $7 \mathrm{p} 21.3$ by radiation hybrid mapping and fluorescence in situ hybridisation. Cytogenet Cell Genet 89: 141-142, 2000.

7. Obacz J, Takacova M, Brychtova V, Dobes P, Pastorekova S, Vojtesek B and Hrstka R: The role of AGR2 and AGR3 in cancer: Similar but not identical. Eur J Cell Biol 94: 139-147, 2015.

8. Higa A, Mulot A, Delom F, Bouchecareilh M, Nguyên DT, Boismenu D, Wise MJ and Chevet E: Role of pro-oncogenic protein disulfide isomerase (PDI) family member anterior gradient 2 (AGR2) in the control of endoplasmic reticulum homeostasis. J Biol Chem 286: 44855-44868, 2011.

9. Ramachandran V, Arumugam T, Wang H and Logsdon CD: Anterior gradient 2 is expressed and secreted during the development of pancreatic cancer and promotes cancer cell survival. Cancer Res 68: 7811-7818, 2008.

10. Ryu J, Park SG, Lee PY, Cho S, Lee DH, Kim GH, Kim JH and Park BC: Dimerization of pro-oncogenic protein anterior gradient 2 is required for the interaction with $\mathrm{BiP} / \mathrm{GRP} 78$. Biochem Biophys Res Commun 430: 610-615, 2013.

11. Oslowski CM and Urano F: Measuring ER stress and the unfolded protein response using mammalian tissue culture system. Methods Enzymol 490: 71-92, 2011.

12. Suh DH, Kim MK, Kim HS, Chung HH and Song YS: Unfolded protein response to autophagy as a promising druggable target for anticancer therapy. Ann N Y Acad Sci 1271: 20-32, 2012.

13. Eizirik DL, Miani M and Cardozo AK: Signalling danger: Endoplasmic reticulum stress and the unfolded protein response in pancreatic islet inflammation. Diabetologia 56: 234-241, 2013.

14. Zhu G and Lee AS: Role of the unfolded protein response, GRP78 and GRP94 in organ homeostasis. J Cell Physiol 230: 1413-1420, 2015.

15. Harding HP, Novoa I, Zhang Y, Zeng H, Wek R, Schapira M and Ron D: Regulated translation initiation controls stress-induced gene expression in mammalian cells. Mol Cell 6: 1099-1108, 2000.

16. Neeb A, Hefele S, Bormann S, Parson W, Adams F, Wolf P, Miernik A, Schoenthaler M, Kroenig M, Wilhelm K, et al: Splice variant transcripts of the anterior gradient 2 gene as a marker of prostate cancer. Oncotarget 5: 8681-8689, 2014.

17. Yosudjai J, Inpad C, Chomwong S, Dana P, Sawanyawisuth K, Phimsen S, Wongkham S, Jirawatnotai S and Kaewkong W: An aberrantly spliced isoform of anterior gradient-2, AGR2 $\mathrm{vH}$ promotes migration and invasion of cholangiocarcinoma cell. Biomed Pharmacother 107: 109-116, 2018.

18. Yosudjai J, Wongkham S, Jirawatnotai S and Kaewkong W: Aberrant mRNA splicing generates oncogenic RNA isoforms and contributes to the development and progression of cholangiocarcinoma. Biomed Rep 10: 147-155, 2019.

19. Thamrongwaranggoon U, Seubwai W, Phoomak C, Sangkhamanonz S, Cha'on U, Boonmars T and Wongkham S: Targeting hexokinase II as a possible therapy for cholangiocarcinoma. Biochem Biophys Res Commun 484: 409-415, 2017.

20. Nami B, Donmez H and Kocak N: Tunicamycin-induced endoplasmic reticulum stress reduces in vitro subpopulation and invasion of CD44+/CD24- phenotype breast cancer stem cells. Exp Toxicol Pathol 68: 419-426, 2016.

21. Li Q, Liu Z, Guo J, Chen J, Yang P, Tian J, Sun J, Zong Y and Qu S: Cholesterol overloading leads to hepatic L02 cell damage through activation of the unfolded protein response. Int J Mol Med 24: 459-464, 2009.

22. Dioufa N, Kassi E, Papavassiliou AG and Kiaris H: Atypical induction of the unfolded protein response by mifepristone. Endocrine 38: 167-173, 2010.

23. Van Schadewijk A, van't Wout EF, Stolk J and Hiemstra PS: A quantitative method for detection of spliced X-box binding protein-1 (XBP1) mRNA as a measure of endoplasmic reticulum (ER) stress. Cell Stress Chaperones 17: 275-279, 2012. 
24. Livak KJ and Schmittgen TD: Analysis of relative gene expression data using real-time quantitative PCR and the 2(Delta Delta C (T)) method. Methods 25: 402-408, 2001

25. Khan A, Gillis K, Clor J and Tyagarajan K: Simplified evaluation of apoptosis using the muse cell analyzer. Postepy Biochem 58: 492-496, 2012

26. Sačková V, Kuliková L, Kello M, Uhrinová I and Fedoročko P: Enhanced antiproliferative and apoptotic response of HT-29 adenocarcinoma cells to combination of photoactivated hypericin and farnesyltransferase inhibitor manumycin A. Int J Mol Sci 12 8388-8405, 2011.

27. Yip NK and Ho WS: Berberine induces apoptosis via the mitochondrial pathway in liver cancer cells. Oncol Rep 30: 1107-1112, 2013.

28. Zheng YM, Shen JZ, Wang Y,Lu AX and Ho WS: Anti-oxidant and anti-cancer activities of Angelica dahurica extract via induction of apoptosis in colon cancer cells. Phytomedicine 23: 1267-1274, 2016.
29. Wang M and Kaufman RJ: The impact of the endoplasmic reticulum protein-folding environment on cancer development. Nat Rev Cancer 14: 581-597, 2014.

30. Dumartin L, Alrawashdeh W, Trabulo SM, Radon TP, Steiger K, Feakins RM, di Magliano MP, Heeschen C, Esposito I, Lemoine NR, et al: ER stress protein AGR2 precedes and is involved in the regulation of pancreatic cancer initiation. Oncogene 36: 3094-3103, 2017.

31. Ron D and Walter P: Signal integration in the endoplasmic reticulum unfolded protein response. Nat Rev Mol Cell Biol 8: 519-529, 2007.

32. Yamamoto K, Sato T, Matsui T, Sato M, Okada T, Yoshida H, Harada A and Mori K: Transcriptional induction of mammalian ER quality control proteins is mediated by single or combined action of ATF6alpha and XBP1. Dev Cell 13: 365-376, 2007.

33. Nishitoh H: CHOP is a multifunctional transcription factor in the ER stress response. J Biochem 151: 217-219, 2012. 